\title{
Meteorological variables and mosquito monitoring are good predictors for infestation trends of Aedes aegypti, the vector of dengue, chikungunya and Zika
}

Danielle Andreza da Cruz Ferreira ${ }^{1 *}$, Carolin Marlen Degener ${ }^{2}$, Cecilia de Almeida Marques-Toledo ${ }^{3,4}$, Maria Mercedes Bendati ${ }^{5}$, Liane Oliveira Fetzer ${ }^{5}$, Camila P. Teixeira $^{6}$ and Álvaro Eduardo Eiras ${ }^{1}$

\begin{abstract}
Background: Aedes aegypti is an important vector for arboviroses and widely distributed throughout the world. Climatic factors can influence vector population dynamics and, consequently, disease transmission. The aim of this study was to characterize the temporal dynamics of an Ae. aegypti population and dengue cases and to investigate the relationship between meteorological variables and mosquito infestation.

Methods: We monitored and analyzed the adult female Ae. aegypti population, the dengue-fever vector, in Porto Alegre, a subtropical city in Brazil using the MI-Dengue system (intelligent dengue monitoring). This system uses sticky traps to monitor weekly infestation indices. We fitted generalized additive models (GAM) with climate variables including precipitation, temperature and humidity, and a GAM that additionally included mosquito abundance in the previous week as an explanatory variable. Logistic regression was used to evaluate the effect of adult mosquito infestation on the probability of dengue occurrence.

Results: Adult mosquito abundance was strongly seasonal, with low infestation indices during the winters and high infestation during the summers. Weekly minimum temperatures above $18^{\circ} \mathrm{C}$ were strongly associated with increased mosquito abundance, whereas humidity above $75 \%$ had a negative effect on abundance. The GAM model that included adult mosquito infestation in the previous week adjusted and predicted the observed data much better than the model which included only meteorological predictor variables. Dengue was also seasonal and $98 \%$ of all cases occurred at times of high adult Ae. aegypti infestation. The probability of dengue occurrence increased by $25 \%$, when the mean number of adult mosquitos caught by monitoring traps increased by 0.1 mosquitoes per week.

Conclusions: The results suggest that continuous monitoring of dengue vector population allows for more reliable predictions of infestation indices. The adult mosquito infestation index was a good predictor of dengue occurrence. Weekly adult dengue vector monitoring is a helpful dengue control strategy in subtropical Brazilian cities.
\end{abstract}

Keywords: Aedes aegypti, Dengue, Surveillance, MosquiTRAP

\footnotetext{
* Correspondence: danielleandreza3@gmail.com

'Departamento de Parasitologia, Instituto de Ciências Biológicas,

Universidade Federal de Minas Gerais, Belo Horizonte, Brazil

Full list of author information is available at the end of the article
} 


\section{Background}

Dengue, the most important vector-borne viral disease for humans, both in terms of morbidity and economic impact, is transmitted by Aedes mosquitoes [1]. It is estimated that 390 million dengue infections occur every year, 96 million of which are symptomatic [2]. More than half of the world's population is at risk of contracting the disease, mainly in urban centers of the tropics and subtropics [3]. The disease has expanded geographically in recent years, so that all four dengue virus serotypes (DENV 1-4) are now circulating in Asia, Africa and the Americas [4], and autochthonous dengue transmission has recently reached southern regions of North America and Europe $[5,6]$. Urbanization, globalization, and increased international travel have contributed to this trend [7]. Predicted climate change scenarios favour a considerable increase of dengue incidence in southern Europe, especially the coastal regions [8] and an increased global distribution of the principal vector $A e$. aegypti in areas that are currently considered to be unfavorable for this species [9].

Other important arboviruses, such as chikungunya [10] and Zika [11] can also be transmitted by Ae aegypti. These two diseases present symptoms similar to dengue, however, Zika virus has recently been associated with Guillain-Barré syndrome in French Polynesia [12] and microcephaly in Brazil $[13,14]$.

Southern Brazil differs from other Brazilian regions by its subtropical climate, which is similar to that of southern Europe and southern United States. Therefore, a Brazilian city of subtropical climate might be a useful model for studying dengue establishment and dynamics in such areas. Systems for continuous disease and vector surveillance are important to further the understanding about the vectordisease mechanisms and disease dynamics $[15,16]$. In our model city Porto Alegre, located in the Brazilian state of Rio Grande do Sul, the dengue vector and imported dengue cases were first detected in 2001 and 2002, respectively, but the first autochthonous dengue cases were confirmed only in 2010, always after the occurrence of imported cases (Coordenadoria Geral de Vigilância em Saúde, CGVS, Porto Alegre, personal communication). This is similar to the situation in some European regions, where dengue has re-emerged, also driven by the introduction of dengue-infected people (tourism and migration) and the invasion of vector mosquito species (revised by Schaffner et al. [17]). Porto Alegre city relied only on fast larval survey (LIRAa) [18] for vector surveillance, which is based on the House Index and is performed only three times per year. After dengue occurrence in 2010 and 2011, the General Health Surveillance Coordination (Coordenadoria Geral de Vigilância em Saúde, CGVS) implemented a large-scale mosquito surveillance system (intelligent dengue monitoring, MI-Dengue) that generates weekly infestation indices [15].
During the past few years, some studies have attempted to model the risk of dengue transmission and vector abundance. Due to the low occurrence of dengue in North American and European countries [19, 20], mosquito population data in these areas are often of limited temporal and spatial resolution and restricted availability. Factors that influence dengue vector abundance and disease occurrence are therefore poorly understood $[17,21]$. It is well known that environmental factors influence diverse aspects of vector and virus biology by interfering with mosquito population dynamics and virus circulation [22, 23]. Furthermore climatic factors such as temperature, humidity, and rain, also affect dengue transmission (reviewed by Morin et al. [24]). However, no study has evaluated the role of these climatic factors in conjunction with vector mosquito abundance and disease surveillance in a region where seasonal autochthonous dengue transmission was recently introduced.

Therefore, the current study investigated the effects of climatic factors on female adult Ae. aegypti abundance and characterized the temporal profile of dengue vector population and disease incidence in a city of humid subtropical climate with a recent history of local dengue transmission. We also examined how the dengue vector density affects the probability of the occurrence of dengue infections. We used data obtained from a large-scale adult mosquito surveillance system that generates weekly infestation indices and maps in real time that is integrated with dengue disease notification in a decision support system $[15,16]$. We further explored and discussed how the inclusion of continuous vector monitoring data improves the fit of vector population models. Our results have implications for dengue forecasting models and may help optimize decision making regarding vector control activities and dengue prevention measures in subtropical areas.

\section{Methods \\ Study area}

Porto Alegre $\left(30^{\circ} 01^{\prime} 40^{\prime \prime} \mathrm{S}, 51^{\circ} 13^{\prime} 43^{\prime \prime} \mathrm{W}\right)$, the capital of the Brazilian State of Rio Grande do Sul, has an area of 496.68 $\mathrm{km}^{2}$, an estimated population of $1,409,351$ inhabitants [25], and a population density of 2,837.53 inhabitants/ $\mathrm{km}^{2}$. The city consists of about $69 \%$ natural environment and $31 \%$ urban area [26]. The climate is classified as humid subtropical according to the Köppen climate classification. This climate class is characterized by precipitation that is well distributed throughout the year [27]. In the summer (December to March), temperatures often reach $35{ }^{\circ} \mathrm{C}$, whereas winter temperatures (June to September) range from $2{ }^{\circ} \mathrm{C}$ to $20{ }^{\circ} \mathrm{C}$. The average annual temperature and rainfall are $19.5{ }^{\circ} \mathrm{C}$ and $1,397 \mathrm{~mm}$, respectively [28].

The study was conducted in 22 of 81 neighborhoods of Porto Alegre city that are using MI-Dengue since 
2012 (Fig. 1a). This area was chosen to implement the monitoring system because it was considered the most vulnerable to disease introduction and occurrence, due to high Ae. aegypti infestation (CGVS, Porto Alegre, personal communication).

\section{MI-Dengue mosquito monitoring system}

MI-Dengue uses the sticky trap MosquiTRAP (Ecovec LTDA, Belo Horizonte, Brazil) to monitor the adult dengue vector population $[15,16]$. The trap contains a synthetic oviposition attractant (AtrAedes) that lures gravid Ae. aegypti. A total of 712 sticky traps were set on fixed outdoor positions, sheltered from rain and sunlight throughout the study area (Fig. 1b), at a distance of approximately $250 \mathrm{~m}$ between each other. The traps were inspected weekly during 173 weeks, from September 2012 to January 2016 (epidemiological weeks $39 / 2012$ to $2 / 2016$ ). The entomological index provided by the sticky trap is the Mean Female Ae. aegypti Index (MFAI, the mean number of Ae. aegypti females per trap). After MI-Dengue was implemented in Porto Alegre city, all neighborhoods addressed their vector control based upon the MFAI index above 0.4 by source reduction.

\section{Meteorological data}

Daily rainfall, temperature parameters (minimum, average and maximum), and average relative air humidity data were obtained from the Brazilian National Institute of Meteorology (INMET). The data were aggregated for epidemiological weeks to accumulated rainfall, and weekly average values of daily minimum, maximum and mean temperature, and minimum humidity (hereafter abbreviated as rain, Tmin, Tmax, Tmean and hum, respectively). Weekly lags of up to four weeks were included in the dataset for all meteorological variables: $\operatorname{Tmin}_{\mathrm{t}}, \operatorname{Tmin}_{\mathrm{t}-1}, \operatorname{Tmin}_{\mathrm{t}-2}, \operatorname{Tmin}_{\mathrm{t}-3}, \operatorname{Tmin}_{\mathrm{t}-4}$ and hum ${ }_{\mathrm{t}}$, hum $_{\mathrm{t}-1}$, hum $_{\mathrm{t}-2}$, humt-3 and humt-4.

\section{Dengue cases}

The Health Secretary of Porto Alegre provided data for confirmed autochthonous dengue cases. The data were organized by epidemiological week, considering the date of first dengue symptoms.

\section{Statistical analysis}

Prior to exploratory analysis and model fitting, the dataset was divided into a training and a test set. The training set, which was used for explanatory data analysis and
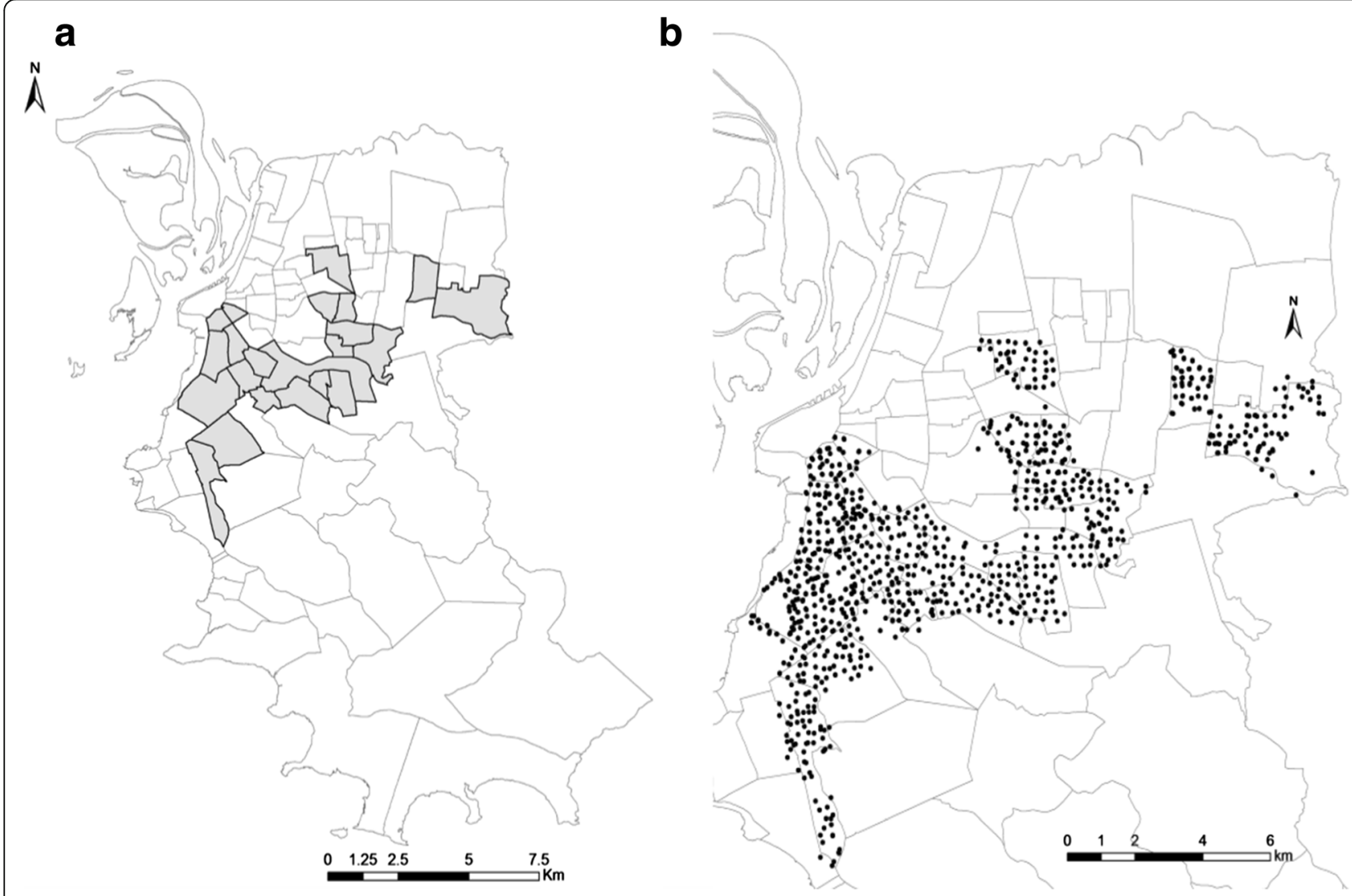

Fig. 1 Study area. a Map of the municipality of Porto Alegre (Rio Grande do Sul), southern Brazil. Lines represent the borders of the neighborhoods. The neighborhoods that are monitored are represented with borders in bold. b Locations of MosquiTRAPs in Porto Alegre (Rio Grande do Sul) 
model fitting, includes the first 144 weeks of the dataset (September 2012 - June 2015). The test set, which was used to compare model predictions to observational records, comprises the last 29 weeks (July 2015 - January 2016).

The relationship between meteorological variables and the number of Ae. aegypti females collected in MosquiTRAPs was first assessed with scatterplots (see Additional file 1: Figure S1). As there was no apparent linear relationship between mosquito catches and the explanatory variables, generalized additive models (GAM) were used to model the data. We used negative binomial models because the response variable (number of Ae. aegypti females collected per week) is overdispersed count data (variance $=102,880.4$, mean $=332.2$ ). Poisson models were also adjusted, but these proved to be inappropriate due to overdispersion. Since the number of weekly monitored traps was not constant, we included the logarithm of the number of monitored traps as the model offset. First, we adjusted several models with a single explanatory variable and identified the best-fitting model for each category of explanatory variables (five models [= number of lags] for each of the following: Tmin, Tmean, Tmax, hum), by comparing the Akaike Information Criterion (AIC) [29] (see Additional file 2: Table S1). We then built multiple models, adding variables in the sequence of increasing AIC of their corresponding simple models. As the three categories of temperature variables (Tmin, Tmean and Tmax) were collinear, we included only $\mathrm{Tmin}_{\mathrm{t}-4}$ in a multiple model, since its corresponding simple regression model had the lowest AIC value.

The interaction between minimum temperature and humidity was also evaluated, but the model without interaction term had a lower AIC value (see Additional file 3: Table S2). The best full model with only meteorological explanatory variables is the following:

$$
\begin{aligned}
& \text { Aaefem }_{t} \sim \text { Binomial Negative }\left(\mu_{t}, k\right) \\
& \begin{aligned}
\log \left(\mu_{t}\right)=\log \left(N_{t}\right)+f_{1}\left(\operatorname{Tmin}_{\mathrm{t}-4}\right) & +f_{2}\left(\text { hum }_{t-4}\right) \\
& +\beta_{0}(\mathrm{M} 1)
\end{aligned}
\end{aligned}
$$

where $\log \left(N_{t}\right)$, the model offset, is the logarithm of the number of traps in week $\mathrm{t}(\mathrm{t}=1, \ldots, 144) ; f_{1}\left(\mathrm{Tmin}_{\mathrm{t}-4}\right)$ and $f_{2}\left(\right.$ hum $\left._{t-4}\right)$ are smooth effects of minimum temperature (lag 4) and humidity (lag 4), respectively; $\beta_{0}$ is the intercept, and $k$ is the dispersion parameter.

The autocorrelation plot of the M1 residues suggests an autocorrelation at lag1. In order to account for the autocorrelation and to investigate if the model's fit improves when mosquito population data collected from the previous week are considered, we adjusted a second model, where we included a smooth effect of the mean number of female Ae. aegypti in the previous week $\left(M F A I_{t-1}\right)$. In this case, humidity lost significance, so that $\mathrm{M} 2$ is given by:

$$
\begin{aligned}
& \text { Aaefem }_{t}^{\sim} \text { Binomial Negative }\left(\mu_{t}, k\right) \\
& \begin{aligned}
\log \left(\mu_{t}\right)=\log \left(N_{t}\right)+f_{1}\left(\operatorname{Tmin}_{\mathrm{t}-4}\right) & +f_{2}\left(M F A I_{t-1}\right) \\
& +\beta_{0}(\mathrm{M} 2)
\end{aligned}
\end{aligned}
$$

The non-linear interaction between $\operatorname{Tmin}_{\mathrm{t}-4}$ and MFAI $_{\mathrm{t}-1}$ was also evaluated. However, the resulting model had a higher AIC value compared to M2.

Adequacy of adjusted GAM models was evaluated through diagnostic residual plots (residuals $v s$ fitted, residuals vs explanatory variables, autocorrelation plot, histogram and quantile-quantile plot of residuals) and by plotting the observed versus predicted data.

Logistic regression was used to investigate how the weekly mean female Aedes index and its lags of one to four weeks $\left(\mathrm{MFAI}_{t}, \mathrm{MFAI}_{t-1}, \mathrm{MFAI}_{t-2}, \mathrm{MFAI}_{t-3}, \mathrm{MFAI}_{t-4}\right)$ affects the occurrence of human dengue cases. The binary response variable was the presence/absence of dengue cases in week $t$. The best lag was chosen based on the lowest AIC value (see Additional file 4: Table S3).

All analyses were performed in the software $\mathrm{R}$, version 3.1.2 using the packages $m g c v$ [30] and MASS [31].

\section{Results}

\section{Descriptive analysis of entomological data}

The sticky traps collected a total of 121,385 mosquitoes between September 2012 and January 2016. The most abundant female mosquitoes were Ae. aegypti (44.0\%) and Culex spp. (38.1\%), whereas Ae. albopictus (3.0\%) was less abundant (Table 1$)$. Male Ae. aegypti $(0.3 \%)$ and Ae. albopictus (0.3\%) constituted a lower proportion of the collected mosquitoes compared to Culex spp. males (14.2\%). A mean ( \pm standard deviation) of $0.43 \pm 1.1 \mathrm{Ae}$. aegypti females were collected per week per trap.

\section{Descriptive temporal analysis}

The weekly minimum and maximum temperatures ranged

\begin{tabular}{|c|c|c|c|}
\hline Species/ stage & Total number (\%) & Range $(n)$ & Mean \pm SD \\
\hline \multicolumn{4}{|l|}{ Aedes aegypti } \\
\hline Female & $53,411(44.0)$ & $0-41$ & $0.43 \pm 1.10$ \\
\hline Male & $415(0.34)$ & $0-9$ & $0.003 \pm 0.07$ \\
\hline \multicolumn{4}{|l|}{ Aedes albopictus } \\
\hline Female & $3,685(3.0)$ & $0-13$ & $0.03 \pm 0.21$ \\
\hline Male & $361(0.3)$ & $0-8$ & $0.003 \pm 0.07$ \\
\hline \multicolumn{4}{|l|}{ Culex spp. } \\
\hline Female & $46,261(38.1)$ & $0-40$ & $0.37 \pm 1.10$ \\
\hline Male & $17,252(14.2)$ & $0-20$ & $0.14 \pm 0.67$ \\
\hline
\end{tabular}
from $4.9{ }^{\circ} \mathrm{C}$ to $24.5{ }^{\circ} \mathrm{C}$ and from $14.1{ }^{\circ} \mathrm{C}$ to $38.0{ }^{\circ} \mathrm{C}$, respectively, and the relative air humidity varied between

Table 1 Descriptive statistics of mosquitoes caught in MosquiTRAPs (MQT) in Porto Alegre, Rio Grande do Sul, Brazil, between September 2012 and January 2016

Abbreviation: $S D$ standard deviation 
61.4 and 93\%. Both temperature and humidity followed a seasonal pattern, whereas rainfall was distributed throughout the years without an apparent pattern (Fig. 2). A descriptive table by year is in Additional file 5: Table S4.

The temporal pattern of female Ae. aegypti abundance was seasonal during all three study years (Fig. 2). Mosquito abundance started to increase in September/ October and decreased in April/May. Every year revealed a high (> 0.5) MFAI between December and April, and the highest value (1.76) was observed in the last week of March 2015. MFAI values close to zero begin to appear in June, remaining so throughout July and August. Mosquito abundance increased approximately two months after the temperature started to increase. Conversely, it began to decline simultaneously with temperature (Fig. 2). Autochthonous dengue cases also displayed a seasonal pattern. Cases occurred at times of high vector infestation and an average temperature above approximately $18{ }^{\circ} \mathrm{C}$, and peaked when the temperature started to decrease. Most of the cases (155/181) occurred in 2013, and only 6 and 20 cases were recorded in 2014 and 2015, respectively. All autochthonous dengue cases, except 10 cases, occurred when the female Ae. aegypti infestation index was above 0.4 (Fig. 2).

\section{Relationship between mosquito abundance and meteorological variables}

All time lags of temperature (Tmin, Tmean and Tmax) and humidity (hum) were significant non-linear explanatory variables of female Ae. aegypti abundance in univariate GAM models $(P<0.05)$ (see Additional file 2: Table $\mathrm{S} 1)$. Rain was only significant at lag1 and approximately negatively linear. The best-fitting models of each category were $\operatorname{Tmean}_{\mathrm{t}-4}, \operatorname{Tmax}_{\mathrm{t}-3}, \operatorname{Tmin}_{\mathrm{t}-4}$ and $h u m_{\mathrm{t}-4}$. The plots of observed versus predicted values of the two best simple GAM models $\left(\operatorname{Tmin}_{\mathrm{t}-4}\right.$ and $\left.h u m_{\mathrm{t}-4}\right)$ are provided in Additional file 6: Figure S2.

The full multiple model (M1) with meteorological variables included the non-linear predictors $\operatorname{Tm}_{\mathrm{t}-4}$ and hum $_{\mathrm{t}-4}$ (Table 2). The model indicates a positive relationship between mosquito abundance and minimum temperature. Above a minimum temperature of about $16{ }^{\circ} \mathrm{C}$, the mosquito catches are above average (Fig. 3a). The effect of $\mathrm{Tmin}_{\mathrm{t}-4}$ on mosquito abundance stabilizes above $19{ }^{\circ} \mathrm{C}$ (approximately horizontal line in Fig. 3a). Mosquito abundance steadily decreased when air humidity was higher than $79 \%$ (Fig. 3b). The plot of observed versus predicted values (Fig. $3 \mathrm{c}$ ) indicates that the model fitted the data well, although it underestimated mosquito abundance in the third year of the study. The predicted values displayed the trend of observed data reasonably, despite the significant over- and underestimation of the mosquito population in some weeks.

The second GAM model (M2) suggests approximately the same relationship between $\mathrm{Tmin}_{\mathrm{t}-4}$ and mosquito abundance, as previously described for M1 (Fig. 4a). Furthermore, the model shows that mosquito abundance increases with increasing $\mathrm{MFAI}_{\mathrm{t}-1}$ values (Fig. 4b). The strongest effects are observed for $\mathrm{MFAI}_{\mathrm{t}-1}$ values below 0.2 , and it stabilizes when $\mathrm{MFAI}_{\mathrm{t}-1}$ values reach 1.0. Figure 4c shows that predictions by the M2 model, which incorporates vector population in the previous week into the model's mathematical equation, fits better to actual population counts $(\mathrm{AIC}=1,628$, proportion deviance explained $=87 \%$ ), compared to $\mathrm{M} 1$, which considers only meteorological predictors $(\mathrm{AIC}=1,735$, proportion deviance explained $=74 \%$ ). The predicted values closely followed the trend of observed data (Fig. 4c), confirming a superior performance of M2 in comparison to M1.

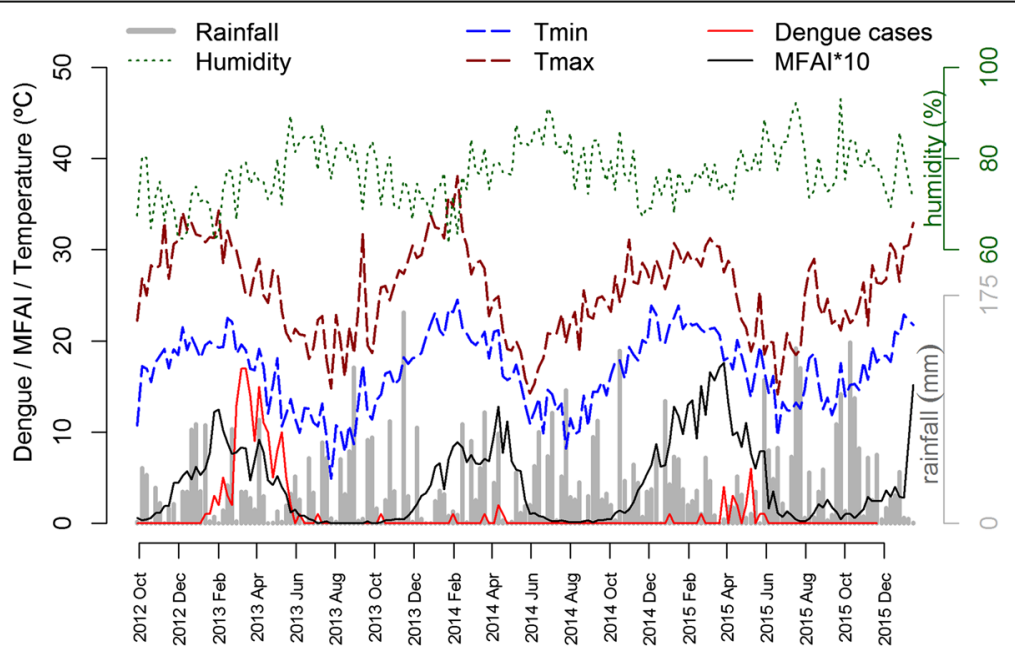

Fig. 2 Time series of dengue cases, mean number of Aedes aegypti females (MFAl), precipitation, minimum and maximum temperature, and humidity in Porto Alegre, between September 2012 and January 2016 
Table 2 Output of the GAM models M1 and M2, and the logistic regression model M3. M1 and $M 2$ are minimal adequate models to explain mosquito abundance, and $\mathrm{M} 3$ is the model to explain presence and absence of dengue cases

\begin{tabular}{|c|c|c|c|c|c|}
\hline Model & Variable & Estimate & Standard Error & $x^{2}$ & $P$-value \\
\hline \multirow[t]{3}{*}{ M1 } & Intercept & -1.477 & 0.058 & & $<0.001$ \\
\hline & $s\left(\operatorname{Tmin}_{\mathrm{t}-4}\right)$ & Smooth & & 352.3 & $<0.001$ \\
\hline & $s($ hum $\mathrm{t}-4)$ & Smooth & & 37.1 & $<0.001$ \\
\hline \multirow[t]{4}{*}{ M2 } & Intercept & -1.590 & 0.038 & & $<0.001$ \\
\hline & $s\left(\operatorname{Tmin}_{\mathrm{t}-4}\right)$ & Smooth & & 27.9 & $<0.001$ \\
\hline & $s\left(\right.$ MAaefem $\left._{\mathrm{t}-1}\right)$ & Smooth & & 296.3 & $<0.001$ \\
\hline & & & & $z$-value & \\
\hline \multirow[t]{2}{*}{ M3 } & Intercept & -2.376 & 0.3835 & -6.196 & $<0.001$ \\
\hline & $M F A I_{t-3}$ & 2.298 & 0.499 & 4.599 & $<0.001$ \\
\hline
\end{tabular}

\section{Relationship between dengue occurrence and mean} female Aedes index (MFAI)

The median MFAI values in the presence and absence of dengue cases were 0.78 and 0.15 , respectively (Fig. 5a). The MFAI in all evaluated lags $\left(M_{F A} I_{t}, M I_{t-1}, M F A I_{t-2}\right.$,
$\left.\mathrm{MFAI}_{\mathrm{t}-3}, \mathrm{MFAI}_{\mathrm{t}-4}\right)$ significantly explained the probability of dengue occurrence (Table 2; Fig. 5b). The best lag was the MFAI of three weeks $\left(\mathrm{MFAI}_{\mathrm{t}-3}\right)$ (see Additional file 4: Table S3), in this lag, the probability of disease occurrence increased by 25\%, when the MFAI increased by 0.1 (Table 2).

\section{Discussion}

In this study, we found that minimum temperature, humidity and previous Ae. aegypti vector density are important factors affecting the temporal pattern of vector abundance in a region of subtropical humid climate in Brazil. Dengue incidence increased significantly with increasing adult female vector infestation.

Weekly mean female Ae. aegypti population numbers in this study followed a seasonal pattern with high infestation in the summer and very low infestation (close to zero or zero) in the winter. A similar pattern has been previously described in subtropical Argentina when using ovitraps, larval indices and larvitraps [32, 33]. Previous longitudinal studies observed intra-annual fluctuations of adult female Ae. aegypti collections in MosquiTRAPs in tropical Brazilian

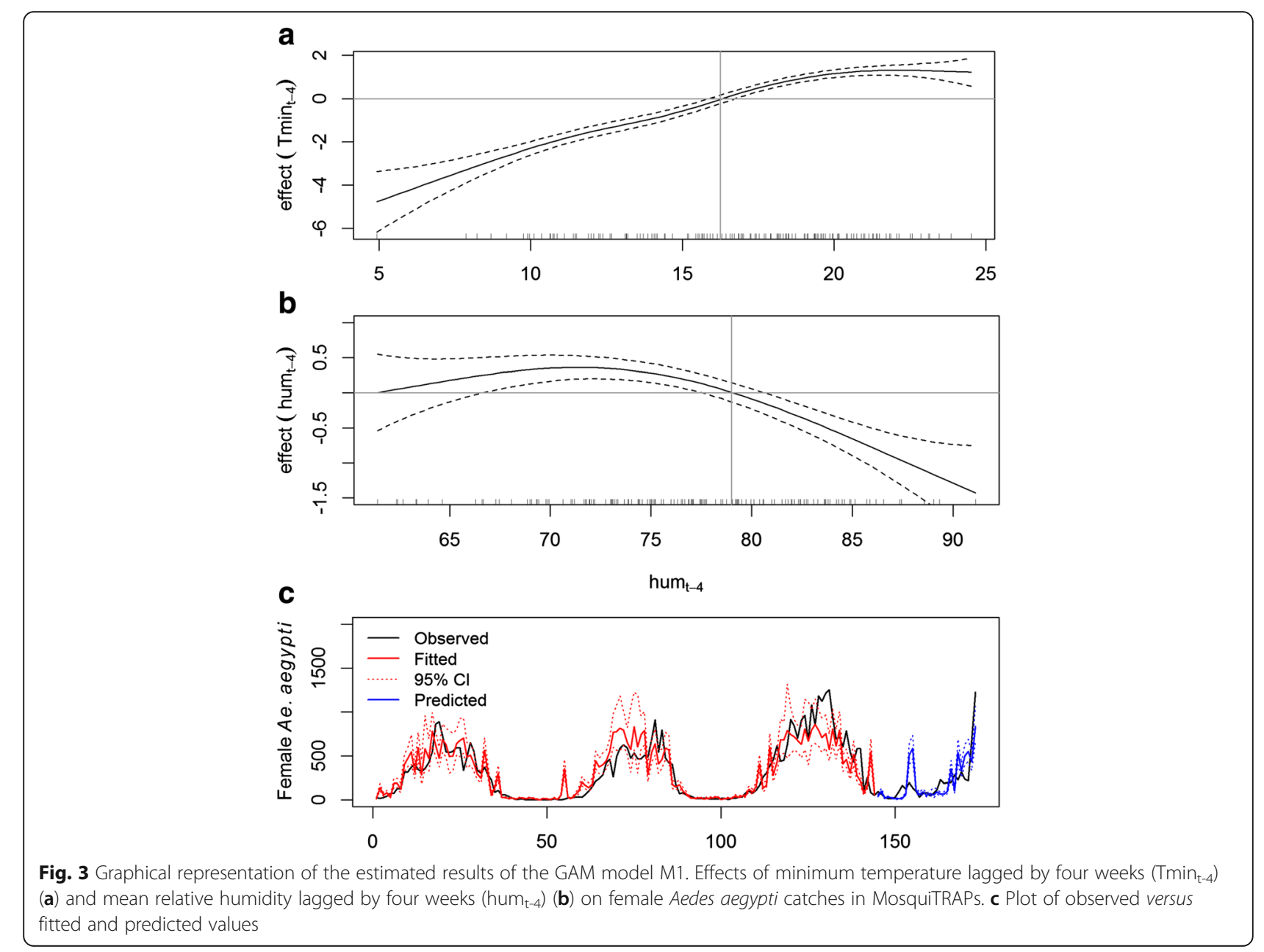



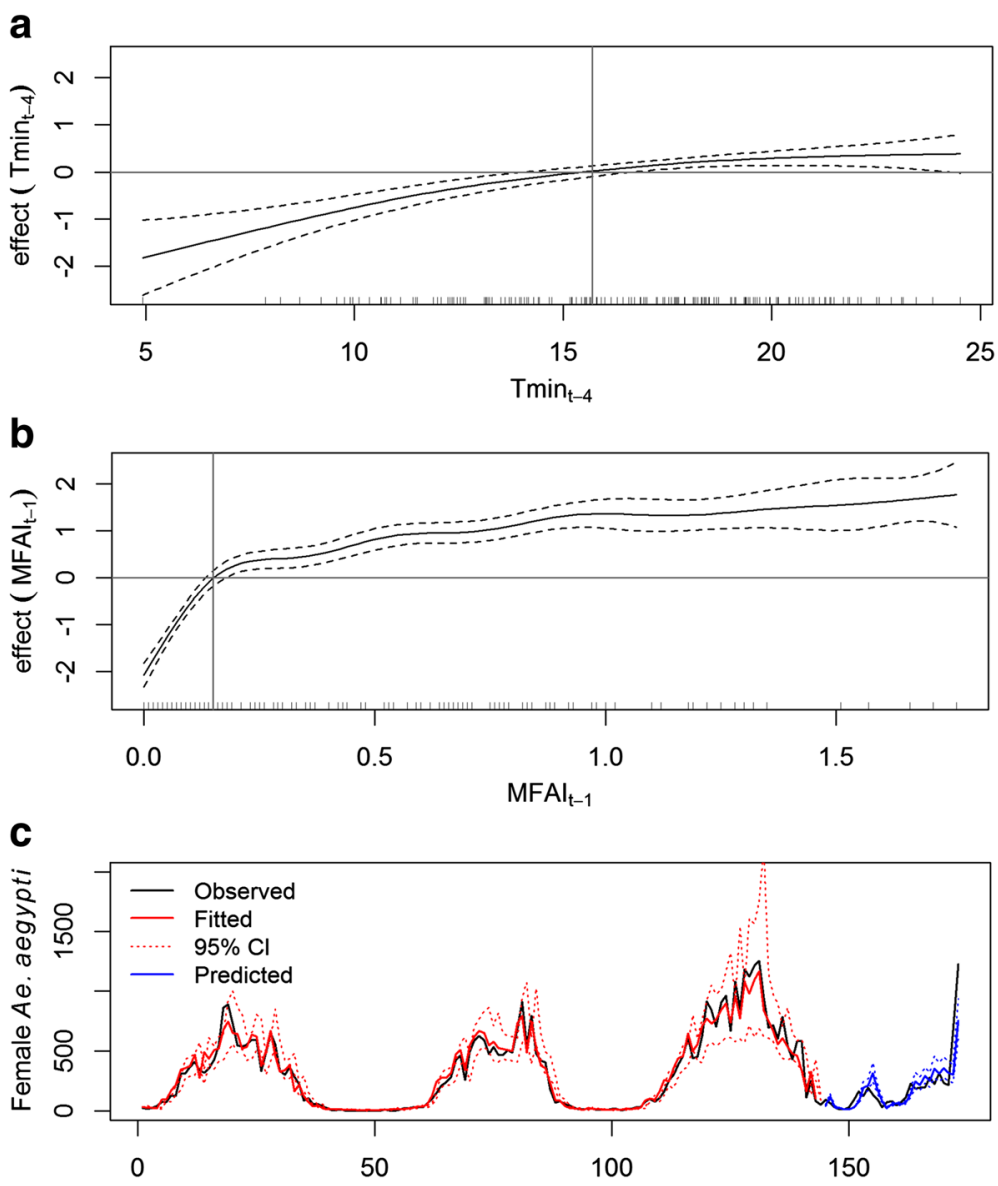

Fig. 4 Graphic representation of the estimated results of the GAM model M2. Effects of minimum temperature lagged by four weeks (Tmin $\left.n_{t-4}\right)(\mathbf{a})$ and of the mean number of female Ae. aegypti caught in the previous week (MFAl $\mathrm{t}_{\mathrm{t}-1}$ ) (b) on female Aedes aegypti catches in MosquiTRAPs. $\mathbf{c}$ Plot of observed versus fitted and predicted values
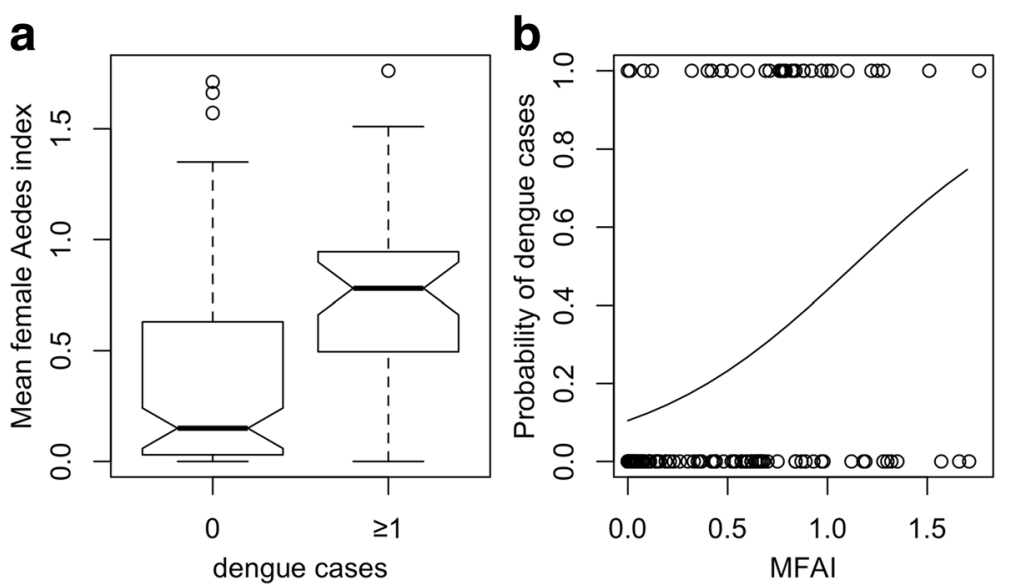

Fig. 5 Relationship between the presence and absence of dengue cases and the mean female Aedes index (MFAl). a Box plots of MFAl conditional on dengue occurrence ( 0 , absence of dengue cases; 1 , presence of dengue cases). $\mathbf{b}$ Graph of the fitted values (solid line) obtained by the logistic regression model applied on the dengue occurrence data. The dots represent the observed values 
cities [34, 35]. However, in these locations, observed infestation indices rarely fell to values close to zero, reflecting a year-round dengue vector infestation. The seasonal pattern of mosquito infestation in our study was related to the seasonality of temperature and humidity. Low temperatures negatively affect dengue vector survival, which leads to a strong fall in vector population. The mean minimum daily temperature in Porto Alegre city was $2{ }^{\circ} \mathrm{C}$ during the winters, with peaks as low as $0{ }^{\circ} \mathrm{C}$, capable of drastically decreasing adult mosquito infestation and viability of laid eggs. Even so, the mosquito population reestablishes during the summers, reaching infestation indices that are similar to and, in some weeks, even higher than in dengue-endemic tropical Brazilian cities (Ecovec LTDA, personal communication). High humidity was associated with low temperature and low mosquito infestation index. Rain was distributed throughout the whole year (characteristic of humid subtropical climate) and, therefore, was not a significant predictor of mosquito abundance.

The multiple GAM model M1 includes non-linear effects of minimum temperature and humidity, both of which lagged by four weeks. The model revealed an approximately linear, positive effect of minimum temperature on mosquito abundance up to approximately $20^{\circ} \mathrm{C}$; above this value, the effect was stable. This means that positive variations in minimum temperatures of up to $20^{\circ} \mathrm{C}$ are associated with growth of the adult vector population, whilst fluctuation in minimum temperatures above $20{ }^{\circ} \mathrm{C}$ did neither increase nor decrease the mosquito population. Since temperature can also influence biting rates [36] and mosquito survival [37], these factors may affect dengue transmission. Humidity had an approximately linear negative effect on the vector population when humidity was above $79 \%$. Humidity is associated with increased Ae. aegypti survival, egg development and biting rates [38-40]. The negative effect that we observed could be due to complex interactions between climatic factors. In our study, humidity was high when temperature was low. Several researchers believe that temperature is the most critical factor for the survival of Ae. aegypti [41-43] and this may explain the negative effect of humidity levels above $79 \%$ upon vector population.

The multiple model M2 includes a non-linear effect of minimum temperature at lag 4 and a non-linear effect of the mean number of female Ae. aegypti per trap with one week lag $\left(M F A I_{\mathrm{t}-1}\right)$. The model indicates that the higher the number of mosquitoes in the previous week, the higher it will be the number in the next week. This effect was most prominent for MFAI values between 0 and 0.2 , reflecting the sharp increase in vector abundance at the beginning of the mosquito proliferation season. The effect of MFAI stagnates at about 1, as MFAI values above 1 were rare. The results indicate that the MFAI model is more accurate and confirm that weekly vector population indices are superior for predicting vector infestation in comparison to using only meteorological predictor variables. Simões et al. [44], who analyzed mosquito infestation data in MosquiTRAPs in a tropical Brazilian city also reinforces the importance of considering previous vector population indices in such models.

The study area includes 22 neighborhoods of the city of Porto Alegre. Although it is an extensive area of the city, where the majority of the population is concentrated, it is important to be careful about the generalization of the results. In small areas there may be diverse microclimates that affect the vector population in different ways in the same interval of time. Future studies should evaluate the city's microclimates, and evaluate for example, if the presence of heat islands affects the abundance and spatiotemporal distribution of dengue vectors and disease cases.

Another limitation of the present study is that we did not consider the effect of mosquito control interventions on the Ae. aegypti population and disease occurrence. Nevertheless this variable could provide information on the effectiveness of actions on the vector population, and could be analyzed in future studies.

The temporal pattern of autochthonous dengue cases was also seasonal. Dengue cases occurred approximately three months after the adult mosquito population began to increase and the peak of dengue cases in 2013 occurred soon after the peak of mosquito infestation. Previous studies analyzing the correlation between dengue incidence and adult Ae. aegypti population showed that high dengue vector infestation precedes high dengue incidence in tropical areas [45-47]. In all three summers in Porto Alegre city, it took two to three months until adult mosquito infestation peaked (MFAI $>0.4$ ), which explains the observed time lag between the increase of mosquito infestation and case occurrence. The two dengue cases that occurred in June and July of 2013, at times when the MFAI had values of 0.08 and 0.00 , respectively, were most likely imported cases.

The logistic regression confirmed that adult Ae. aegypti infestation is closely associated with subsequent dengue occurrence. Our results suggest that the weekly dengue cases increase by $25 \%$, when the mosquito infestation increases by 0.1 . Previous studies investigating the correlation between dengue cases and immature mosquito development stages (larvae and pupae) reported an absence or low correlation with dengue incidence $[48,49]$, indicating that the adult dengue vector monitoring is a better predictor for dengue transmission.

Due to the low total number of dengue cases, especially in 2014 and 2015, a rigorous analysis of the association between disease transmission and meteorological predictor variables was unviable. We observed, however, that cases occurred predominantly when the average temperature was above $18{ }^{\circ} \mathrm{C}$. In subtropical Taiwan, months with temperatures above 
$18{ }^{\circ} \mathrm{C}$ are also associated with high risk of dengue transmission [50].

The higher number of autochthonous dengue cases in 2013, which peaked when the temperature was beginning to decrease, may suggest that besides the high vector abundance, other elements favored transmission [51]. One likely important factor was the number of imported cases in January and February (holiday season), which occurred about one week before a pronounced increase of autochthonous cases (CGVS, unpublished data). The February holiday (carnival) occurs during the dengue season in most Brazilian States and 2013 was a record epidemic year. During this time, a high number of Brazilian and foreign visitors, including from dengue-endemic cities, traveled all over Brazil. Since most dengue infections are asymptomatic $[52,53]$, the probability of traveling whilst being infected is relatively high, contributing to viral dissemination to other regions. Human migration patterns not only due to holidays, but also because of economic crises and wars, to name a few, appear to be important factors for estimating the likelihood importing dengue to non-endemic areas. As seen in Porto Alegre and several European and North American settings [5, 6, 54, 55], imported cases can lead to the occurrence of local transmission of diseases, when competent vector populations of Ae. aegypti and/or Ae. albopictus is present.

Another factor likely to be associated with a relatively high number of cases in 2013, when compared to 2014 and 2015 is that 2013 was the year the highest number of dengue cases in Brazil, which increased the probability of introduction of imported cases. The notification and confirmation delay of the dengue cases is the main cause of late application of control strategies. In such situations, MI-Dengue can be a good tool to detect high infestation of Ae. aegypti and to direct activities based on the vector index. However, no previous data from MI-Dengue monitoring was available for an area of subtropical climate, and the MFAI was not yet evaluated for this kind of scenario (Ecovec LTDA, personal communication). After three years of mosquito monitoring, we can validate the mosquito index MFAI, together with minimum temperature data, as good predictors for vector infestation and dengue incidence levels.

\section{Conclusions}

The current study shows that minimum temperature and humidity are important meteorological variables that affect Ae. aegypti population dynamics. Furthermore, a model that includes data from continuous adult mosquito monitoring in addition to meteorological data adjusts and predicts the mosquito population substantially improved. We also found a strong association between female mosquito abundance and dengue case occurrence. Dengue transmission has complex dynamics, and climate factors and entomological monitoring are only a part of the disease's determinants. Other factors, such as human movement patterns and epidemiological information (circulation serotypes, herd immunity), should also be considered for the development of reliable predictive models that estimate dengue spatio-temporal distribution in areas where it is not yet epidemic.

\section{Additional files}

Additional file 1: Figure S1. Scatterplots of the MFAl (mean number of Ae. aegypti females) against each of the explanatory variables. A smoothing (LOESS) curve was added in each panel. (PDF $100 \mathrm{~kb}$ )

Additional file 2: Table S1. Comparison of AlCs of models with variables and varying time lags. (PDF $233 \mathrm{~kb}$ )

Additional file 3: Table S2. Comparison of discarded models. (PDF $118 \mathrm{~kb}$ ) Additional file 4: Table S3. Comparison of AlCs of logistic regression models with MFAl as predictor variable in varying time lags. (PDF $83 \mathrm{~kb}$ )

Additional file 5: Table S4. Descriptive statistics by year. ${ }^{*}$ The year 2012 includes only data from September onwards, and year 2016 includes only data until January. (PDF 28 kb)

Additional file 6: Figure S2. Observed and fitted by model: a gam (Aaefem $\sim$ offset(INtraps) $+\mathrm{s}($ Tmin 4$)+s($ hum4), family $=$ nb 0). b gam (Aaefem $\sim$ offset(INtraps) + s(hum4), family = nb 0), c gam (Aaefem $\sim$ offset(INtraps) + $\mathrm{s}($ Tmin4), family $=\mathrm{nb}$ ()). (PDF $275 \mathrm{~kb})$

\section{Abbreviations}

AIC: Akaike information criterion; CGVS: Coordenadoria Geral de Vigilância em Saúde; DENV: Dengue virus serotypes; GAM: Generalized additive models; INMET: Brazilian National Institute of Meteorology; LIRAa: Levantamento Rápido de Índices para Aedes aegypti; MFAl: Mean female Aedes index; MI-DENGUE: Intelligent dengue monitoring

\section{Acknowledgements}

We thank all field workers who made sticky trap inspections and residents who allowed the installation of traps. We are also grateful to Ecovec and the Porto Alegre Health Department for providing the mosquito monitoring data. We are indebted to Cláudia Torres Codeço for her valuable suggestions on data analysis.

\section{Funding}

DACF, CMD, and AEE received fellowships from CNPq (Conselho Nacional de Desenvolvimento Científico e Tecnológico) and FAPEMIG (Fundação de Amparo a Pesquisa do Estado de Minas Gerais). This project was funded by CNPq/DECIT-MS (Grant \# 404211/2012-7), and CAPES (Grant \# 3048-2011).

\section{Availability of data and material}

The data supporting the conclusions of this article are included within the article and its additional files. Raw data are available from the authors on request.

\section{Authors' contributions}

Designed this study and critically revised the manuscript: AEE, CPT, DACF, CMD. Analyzed the data: CMD, DACF. Drafted the manuscript AEE, DACF, CMD, CAMT. Participated in manuscript revision: AEE, MMB and LOF. All authors read and approved the final manuscript.

\section{Competing interests}

The authors declare that they have no competing interests.

\section{Consent for publication}

Not applicable.

\section{Ethics approval}

The study was reviewed and approved by the Ethical Committee of the Federal University of Minas Gerais, Belo Horizonteand Health Secretary of Porto Alegre, Brazil (CAAE n. 3699 1014.7.0000.5149). 


\section{Author details}

'Departamento de Parasitologia, Instituto de Ciências Biológicas, Universidade Federal de Minas Gerais, Belo Horizonte, Brazil. ${ }^{2}$ Programa de Computação Científica, Fiocruz, Rio de Janeiro, Brazil. ${ }^{3}$ Ecovec Ltda., Parque Tecnológico de Belo Horizonte (BHTec) Belo Horizonte, Belo Horizonte, Brazil. ${ }^{4}$ Departamento de Bioquímica e Imunologia, ICB, Universidade Federal de Minas Gerais, Belo Horizonte, Brazil. ${ }^{5}$ Vigilância de Roedores e Vetores, CGVS/ SMS, Porto Alegre, Brazil. ${ }^{6}$ UNIFEMM, Sete Lagoas, Brazil.

Received: 20 July 2016 Accepted: 8 February 2017 Published online: 13 February 2017

\section{References}

1. Gubler DJ. The economic burden of dengue. Am J Trop Med Hyg. 2012;86:743-4.

2. Bhatt S, Gething PW, Brady OJ, Messina JP, Farlow AW, Moyes CL, et al. The global distribution and burden of dengue. Nature. 2013;496:504-7.

3. WHO. Global Strategy for Dengue Prevention and Control 2012-2020. Geneva: World Health Organization; 2012.

4. Guzman MG, Halstead SB, Artsob H, Buchy P, Farrar J, Gubler DJ, et al. Dengue: a continuing global threat. Nat Rev Microbiol. 2010;8:1-26.

5. Lourenço J, Recker M. The 2012 Madeira dengue outbreak: Epidemiological determinants and future epidemic potential. PLoS Negl Trop Dis. 2014;8:e3083.

6. Teets FD, Ramgopal MN, Sweeney KD, Graham AS, Michael SF, Isern S. Origin of the dengue virus outbreak in Martin Country, Florida, USA 2013. Virol Rep. 2014;1-2:2-8.

7. Murray NEA, Quam MB, Wilder-Smith A. Epidemiology of dengue: Past present and future prospects. Clin Epidemiol. 2013;5:299-309.

8. Bouzid M, Colón-González FJ, Lung T, Lake IR, Hunter PR. Climate change and the emergence of vector-borne diseases in Europe: case study of dengue fever. BMC Public Health. 2014;14:781.

9. Khormi HM, Kumar L. Climate change and the potential global distribution of Aedes aegypti: spatial modelling using geographical information system and CLIMEX. Geospat Health. 2014:8:405-15.

10. De Figueiredo MLG, Figueiredo LTM. Emerging alphaviruses in the Americas: Chikungunya and Mayaro. Rev Soc Bras Med Trop. 2014;47:677-83.

11. Marchette NJ, Garcia R, Rudnick A. Isolation of Zika virus from Aedes aegypti mosquitoes in Malaysia. Am J Trop Med Hyg. 1969:18(3):411-5.

12. Oehler E, Watrin L, Larre P, Leparc-Goffart I, Lastere S, Valour F, Baudouin L, Mallet HP, Musso D, Ghawche F. Zika virus infection complicated by Guillain-Barre syndrome - case report, French Polynesia, December 2013. Euro Surveill. 2014;19:7-9.

13. European Centre for Disease Prevention and Control. Rapid risk assessment: Microcephaly in Brazil potentially linked to the Zika virus epidemic - 24 November 2015. Stockholm: ECDC; 2015 Available from: http://ecdc.europa. eu/en/publications/Publications/zika-microcephaly-Brazil-rapid-riskassessment-Nov-2015.pdf. Accessed 20 Feb 2016

14. Marcondes CB, Ximenes M de FF de M. Zika virus in Brazil and the danger of infestation by Aedes (Stegomyia) mosquitoes. Rev Soc Bras Med Trop. 2015; 49(1):4-10.

15. Eiras ÁE, Resende MC De. Preliminary evaluation of the "Dengue-MI" technology for Aedes aegypti monitoring and control. Cad. Saúde Pública. 2009; 25:45-58.

16. Pepin KM, Marques-toledo $C$, Scherer L, Morais MM, Ellis B, Eiras AE. Costeffectiveness of novel system of mosquito surveillance. Emerg Infect Dis. 2013;19:542-50.

17. Schaffner F, Mathis A. Dengue and dengue vectors in the WHO European region: past, present, and scenarios for the future. Lancet Infect Dis. 2014; 14:1271-80

18. MS-Ministério da Saúde. Secretaria de Vigilância em Saúde. Levantamento Rápido de Índices para Aedes aegypti - LIRAa - para vigilância entomológica do Aedes aegypti no Brasil - Metodologia para avaliação dos índices de Breteau e Predial e Tipo de recipientes. 2013; Brasília. Available from: http:// bvsms.saude.gov.br/bvs/publicacoes/levantamento_rapido_indices_aedes_ aegypti.pdf. Acessed 20 Dec. 2015.

19. Dengue epidemiology. Center for Disease Control and Prevention (CDC) 2014. Available from: http://www.cdc.gov/dengue/epidemiology/. Accessed 31 Jan 2016.

20. European Centre for Disease Prevention and Control. Annual epidemiological report 2014 - emerging and vector-borne diseases. 2014;30-4. http://ecdc. europa.eu/en/publications/Publications/emerging-vector-borne-diseases_ annual-epidemiological-report-2014.pdf. Accessed 25 Nov 2015.
21. Hii YL, Ahmad Z R, Aghamohammadi N, Rocklöv J. Research on Climate and Dengue in Malaysia: A Systematic Review. Curr Environ Health Rep. 2016;3:81-90,

22. Kuno G. Review of the factors modulating dengue transmission. Epidemiol Rev. 1995:17:321-35.

23. Descloux E, Mangeas M, Menkes CE, Lengaigne M, Leroy A, Tehei T, et al. Climate-based models for understanding and forecasting dengue epidemics. PLoS Negl Trop Dis. 2012;6:e1470.

24. Morin CW, Comrie AC, Ernst K. Climate and dengue transmission: Evidence and implications. Environ Health Perspect. 2013;121:1264-72.

25. IBGE-Instituto Brasileiro de Geografia e Estatística. Censo 2010. Available from: http://cidades.ibge.gov.br/painel/painel.php?codmun=431490 Accessed 15 Jul 2014.

26. Secretaria Municipal do meio ambiente. Diagnóstico Ambiental de Porto Alegre: Geologia, Solos, Drenagem, Vegetação/Ocupação e Paisagem. Porto Alegre: Secretaria Municipal do Meio Ambiente; 2008.

27. Alvares CA, Stape JL, Sentelhas PC, De Moraes Gonçalves JL, Sparovek G. Köppen's climate classification map for Brazil. Meteorol Z. 2013:22:711-28.

28. Clima: Porto Alegre. Climated-data.org. Available from: http://pt.climate-data. org/location/3845/). Accessed 21 Dec 2015.

29. Akaike $\mathrm{H}$. A new look at the statistical model identification. IEEE Trans Autom Control. 1974;19:716-23.

30. Wood SN. Generalized Additive Models: An Introduction with R. Chapman and Hall/CRC. 2006

31. Venables WN, Ripley BD. Modern Applied Statistics with S. New York: Springer; 2002.

32. Micieli MV, Campos RE. Oviposition activity and seasonal pattern of a population of Aedes (Stegomyia) aegypti (L.) (Diptera: Culicidae) in subtropical Argentina. Mem Inst Oswaldo Cruz. 2003;98:659-63.

33. Vezzani D, Velázquez SM, Schweigmann N. Seasonal pattern of abundance of Aedes aegypti (Diptera: Culicidae) in Buenos Aires City, Argentina. Mem Inst Oswaldo Cruz. 2004;99:351-6.

34. Honório NA, Codeço CT, Alves FC, Magalhães MA FM, Lourenço-De-Oliveira R. Temporal distribution of Aedes aegypti in different districts of Rio de Janeiro, Brazil, measured by two types of traps. J Med Entomol. 2009;46:1001-14.

35. Degener CM, De Ázara TMF, Roque RA, Codeço CT, Nobre AA, Ohly JJ, et al. Temporal abundance of Aedes aegypti in Manaus, Brazil, measured by two trap types for adult mosquitoes. Mem Inst Oswaldo Cruz. 2014;109:1030-40.

36. Luz PM, Mendes BVM, Codeço CT, Struchiner CJ, Galvani AP. Time series analysis of dengue incidence in Rio de Janeiro, Brazil. Am J Trop Med Hyg. 2008;79:933-9.

37. Tun-Lin W, Burkot T, Kay H. Effects of temperature and larval diet on development rates and survival of the dengue vector Aedes aegypti in north Queensland, Australia. Med Vet Entomol. 2000;14:31-7.

38. Christophers SR. Aedes aegypti (L.), The yellow fever mosquito: its life history, bionomics and structure. Cambridge: Cambridge University Press; 1960.

39. Azil AH, Long SA, Ritchie SA, Williams CR. The development of predictive tools for pre-emptive dengue vector control : a study of Aedes aegypti abundance and meteorological variables in North Queensland, Australia. Trop Med Int Heal. 2010;15:1190-7.

40. Costa EAPDA, Santos EMDM, Correia JC, De Albuquerque CMR. Impact of small variations in temperature and humidity on the reproductive activity and survival of Aedes aegypti (Diptera, Culicidae). Rev Bras Entomol. 2010;54:488-93.

41. Couret J, Benedict MQ. A meta-analysis of the factors influencing development rate variation in Aedes aegypti (Diptera: Culicidae). BMC Ecol. 2014;14:3.

42. Alto BW, Bettinardi D. Temperature and dengue virus infection in mosquitoes: Independent effects on the immature and adult stages. Am J Trop Med Hyg. 2013;88:497-505.

43. Brady OJ, Johansson MA, Guerra CA, Bhatt S, Golding N, Pigott DM, et al. Modelling adult Aedes aegypti and Aedes albopictus survival at different temperatures in laboratory and field settings. Parasit Vectors. 2013;6:351.

44. Simões TC, Codeço $\subset$, Nobre AA, Eiras ÁE. Modeling the non-stationary climate dependent temporal dynamics of Aedes aegypti. PLoS One. 2013;8:e64773.

45. Barrera R, Amador M, MacKay AJ. Population dynamics of Aedes aegypti and dengue asinfluenced by weather and human behavior in San Juan, Puerto Rico. PLoS Negl Trop Dis. 2011;5:e1378.

46. Rubio-Palis Y, Perez-Ybarra LM, Infante-Ruiz M, Comach G. UrdanetaMarquez $L$. Influence of climatic variables on dengue cases and abundance of Aedes aegypti (Diptera: Culicidae) in Maracay, Venezuela. Bol Mal Salud Amb. 2011;51:145-57.

47. Dibo MR, Chierotti AP, Ferrari MS, Mendonça AL, Neto FC. Study of the relationship between Aedes (Stegomyia) aegypti egg and adult densities, 
dengue fever and climate in Mirassol, state of São Paulo, Brazil. Mem Inst Oswaldo Cruz. 2008;103:554-60.

48. Coelho GE, Burattini MN, Teixeira G, Antonio F, Coutinho B, Massad E. Dynamics of the 2006/2007 denque outbreak in Brazil. Mem Inst Oswaldo Cruz. 2008;103:535-9.

49. Arboleda S, Jaramillo NO, Peterson AT. Spatial and temporal dynamics of Aedes aegypti larval sites in Bello, Colombia. J Vector Ecol. 2012;37:37-48.

50. Wu P, Lay J, Guo H, Lin C, Lung S, Su H. Higher temperature and urbanization affect the spatial patterns of dengue fever transmission in subtropical Taiwan. Sci Total Environ. 2009;407:2224-33.

51. Banu S, Hu W, Hurst C, Tong S. Dengue transmission in the Asia-Pacific region: impact of climate change and socio- environmental factors. Trop Med Int Heal. 2011;16:598-607.

52. Yoon IK, Rothman AL, Tannitisupawong D, Srikiatkhachorn A, Jarman RG, Aldstadt J, et al. Underrecognized mildly symptomatic viremic dengue virus infections in rural Thai schools and villages. J Infect Dis. 2012;206:389-98.

53. Gordon A, Kuan G, Mercado JC, Gresh L, Avilés W, Balmaseda A, Harris E. The Nicaraguan pediatric dengue cohort study: Incidence of inapparent and symptomatic dengue virus infections, 2004-2010. PLoS Negl Trop Dis. 2013; 7:2004-10.

54. La Ruche $G$, Souarès $Y$, Armengaud $A$, Peloux-Petiot $F$, Delaunay $P$, Desprès $P$, et al. First two autochthonous dengue virus infections in metropolitan France, September 2010. Euro Surveill. 2010;15(39):19676.

55. Gjenero-Margan I, Aleraj B, Krajcar D, Lesnikar V, Klobučar A, Pem-Novosel I, et al. Autochthonous dengue fever in Croatia, August- September 2010. Euro Surveill. 2011;16(9):19805.

\section{Submit your next manuscript to BioMed Central} and we will help you at every step:

- We accept pre-submission inquiries

- Our selector tool helps you to find the most relevant journal

- We provide round the clock customer support

- Convenient online submission

- Thorough peer review

- Inclusion in PubMed and all major indexing services

- Maximum visibility for your research

Submit your manuscript at www.biomedcentral.com/submit
C Biomed Central 